\title{
Hydrothermal Preparation of Silver Doping Zinc Oxide Nanoparticles: Studys, Characterization and Photocatalytic Activity
}

\author{
HASSAN A. HABEEB ALSHAMSI* and BATOOL S. HUSSEIN \\ Department of Chemistry, College of Education, University of Al-Qadisiyah, \\ Post Box 88, Diwaniya, Iraq. \\ ${ }^{*}$ Corresponding author E-mail: hasanchem70 @ gmail.com \\ http://dx.doi.org/10.13005/ojc/3404025
}

(Received: July 03, 2017; Accepted: June 27, 2018)

\begin{abstract}
In this study, we report the prepared of $\mathrm{ZnO}$ nanoparticles and Ag doped $\mathrm{ZnO}$ nanostructure via a hydrothermal process. The obtained nanostructures were characterized using different characterization techniques such as X-ray diffraction (XRD), transmission electron microscopy (TEM), scanning electron microscopy (SEM), energy dispersive spectroscopy (EDS), atomic force microscopy (AFM), Fourier transform infrared spectrometry (FTIR) and UV/Visible spectrophotometer. The XRD results showed the wurtzite hexagonal structure of the ZnO Nanoparticles. Furthermore, the morphology of $\mathrm{ZnO}$ and $\mathrm{Ag}-\mathrm{ZnO}$ nanostructures was obtained from SEM and AFM. The photocatalytic degradation of Cibacron Brilliant Yellow 3G-P (CB) dye was studied in presence of visible light using $\mathrm{Ag}-\mathrm{ZnO}$ nanostructures as a photocatalyst.There are numerous factors which has an effect on the efficiency color removal of this process. Hence a study was conducted on the effect of several parameters on $\mathrm{Ag}-\mathrm{ZnO}$ like amount of catalyst, $\mathrm{CB}$ dye concentration and $\mathrm{pH}$ of solution. Results showed Ag doping $\mathrm{ZnO}$ with 3\% loading shows photocatalytic removal about $65 \%$ after $120 \mathrm{~min}$. which influenced superior photocatalytic activity than pure $\mathrm{ZnO}$.
\end{abstract}

Keyword: Hydrothermal, Nanoparticles, Characterization, Photocatalytic.

\section{INTRODUCTION}

Recently, Metal oxide nanoparticles have been involved consideration in various fields of scientific and technological applications because of unique electrical, mechanical, chemical and optical properties from their particle sizes in nanoscale ${ }^{1-2}$. $\mathrm{ZnO}$ is one of the most significant nanomaterial that have been widely studied for many decades, which have a wide band gap (3.37eV) that's make semiconductor transparent in visible light and works in the UV region to blue wavelengths also the higher exciton binding energy $(60 \mathrm{meV})$ at room temperature improves its luminescence efficiency of light discharge, In materials science $\mathrm{ZnO}$ is identify as one of the well-known n-type metal oxide semiconductor ${ }^{3-5}$. Decrease in size of bulk to nano scale introduced novel properties

This is an Open Access article licensed under a Creative Commons Attribution-Non Commercial-Share Alike 4.0 International License (https://creativecommons.org/licenses/by-nc-sa/4.0/), which permits unrestricted Non Commercial use, distribution and reproduction in any medium, provided the original work is properly cited. 
to $\mathrm{ZnO}$ nanomaterial because of the surface area and quantum effect lead to provide $\mathrm{ZnO}$ some advantages as very important material in the different treatment of gas sensors, field transistors, light emitting devices and solar cells ${ }^{6-8}$. Zinc oxide exhibits high efficiency than $\mathrm{TiO}_{2}$ in presence UV light due to $\mathrm{ZnO}$ can absorb UV light at wavelength $\geq 385 \mathrm{~nm}$, Though, for higher photocatalytic effectiveness and numerous practical applications, it is require that photocatalyst for example $\mathrm{ZnO}$ should absorb UV in addition to absorb visible light due to the fact that UV light less than $10 \%$ of energy in the solar radiation while visible light record for $45 \%$ in solar radiation. When $\mathrm{ZnO}$ absorb the visible light lead to make band gap of zinc oxide be narrowed and split into many act gaps, which can be attained by doping nitrogen or incorporated with transition metal ions ${ }^{9-11}$.Silver nanoparticles have been unique physicochemical such as structural, optical and electrical properties, Also silver doped $\mathrm{ZnO}$ nano crystallites could improve the photocatalytic activity of $\mathrm{ZnO}$ in some cases ${ }^{12}$. Degradation of dyes is a method in which the bulky molecules of dye are destroyed into smaller molecules such as water, $\mathrm{CO}_{2}$ and mineral by products. In photocatalysis, when $\mathrm{ZnO}$ absorbs photons of energy equal or above its bandgap, electron-hole pairs are generated that induce redox reactions at its surface by react with $\mathrm{O}_{2}$ and $\mathrm{H}_{2} \mathrm{O}$ molecules to form superoxides anions and $\bullet \mathrm{OH}$ radical . Many metal oxides such as $\mathrm{ZnO}$, $\mathrm{TiO}_{2}, \mathrm{Fe}_{2} \mathrm{O}_{3}$ and $\mathrm{WO}_{3}$, etc. have been used as photocatalyst to removal different organic dyes ${ }^{13-}$ 14. Diverse methods used for synthesis of $\mathrm{ZnO}$ nanostructures such as hydrothermal synthesis ${ }^{15-}$ ${ }^{16}$, chemical or physical vapor deposition 17 , precipitation in water solution ${ }^{18}$, the sol-gel process ${ }^{19}$. However, Variation of morphology of zinc oxide nanoparticles with particles makes it probable to differing in shape, size and spatial structure ${ }^{20}$. The hydrothermal synthesis is becoming one of the most significant tools for nanomaterial's processing, usually conducted in steel pressure vessels named autoclaves using with or without Teflon liners in presence high pressure and controlled temperature, the reaction in aqueous solution of solvents or mineralizers. The temperature can be higher above the boiling point of water, attainment the pressure of vapour saturation, usually carried out below $300^{\circ} \mathrm{C}^{21-22}$. In this work, the simple hydrothermal method was used to obtain the $\mathrm{Ag}$ doped and undoped $\mathrm{ZnO}$ nanostructure. Photocatalytic activity of $\mathrm{ZnO}$ and $\mathrm{Ag}-\mathrm{ZnO}$ nanostructure which studied using Cibacron Brilliant Yellow 3G-P CB dye in presence visible light, the effect of diverse parameters on $\mathrm{Ag}-\mathrm{ZnO}$ nanostructure such as amount of $\mathrm{Ag}-\mathrm{ZnO}$ catalyst, concentration of $\mathrm{CB}$ dye and $\mathrm{pH}$ of solution also studied, Also The photo degraded samples were analyzed by chemical oxygen demand (COD) analysis.

\section{EXPERIMENTAL}

\section{Materials}

The chemicals used are zinc nitrate hexahydrate $\left(\left[\mathrm{Zn}\left(\mathrm{NO}_{3}\right)_{2} \bullet 6 \mathrm{H}_{2} \mathrm{O}\right], 99.9 \%\right)$ from Scharlau, silver nitrate $\left(\mathrm{AgNO}_{3}, 99.8 \%\right)$ was obtained from Sigma-Aldrich).Cibacron Brilliant Yellow 3G-P dye $(99 \%)$, F.wt $=872.97$ from (Sigma-Aldrich) $\lambda \max =404 \mathrm{~nm}$, The structure formula of dye was shown in Fig.1 .Absolute ethanol $\left(\mathrm{C}_{2} \mathrm{H}_{6} \mathrm{O}, 99.9 \%\right)$, hydrochloric acid (37\%) and sodium hydroxide (99\%) were obtained from $\mathrm{BDH}$. All chemicals were used in their original form without further purification.<smiles></smiles>

Fig.1. Structure Formula of Cibacron Brilliant Yellow 3G-P

\section{Preparation of Zinc oxide Nanoparticle}

The hydrothermal method was used to prepared the $\mathrm{ZnO}$ nanoparticles. In this method, $1.785 \mathrm{~g}$ of zinc nitrate hexahydrate dissolving in $20 \mathrm{ml}$ of deionized water solutions were slowly dripped into $\mathrm{NaOH}(0.01 \mathrm{M})$ solution and the mixture was stirred continuously for $2 \mathrm{~h}$ at $\mathrm{pH}=8.5$, A white precipitate was formed. The precipitate resulting from the reaction between the two solutions was allowed to settle down for $24 \mathrm{~h}$, the solution was put in a stainless steel autoclave for carrying out the hydrothermal treatment at $180^{\circ} \mathrm{C}$ for 4 hours. The stainless steel autoclave was then opened at 
room temperature and the precipitate was separated and washed repeatedly by deionized water until the $\mathrm{pH}=7$ and sonicated for $10 \mathrm{~min}$. to get uniformly $\mathrm{ZnO}$ nanoparticles suspension. This suspension was centrifuged and dried at $80{ }^{\circ} \mathrm{C}$ for $3 \mathrm{~h}$ and then ground to get a fine powder, finally calcinated for $4 \mathrm{~h}$ at $350^{\circ} \mathrm{C}^{23}$.

\section{Preparation of Ag doped $\mathrm{ZnO}$ nanostructure}

$\mathrm{Ag}-\mathrm{ZnO}$ nanostructure with different molar ratios (0.03:0.97, $\mathrm{Ag} / \mathrm{Zn} \%$ ) was prepared by using a hydrothermal method. Typically, Ag-ZnO composites was synthesized as follows: $4.412 \mathrm{~g}$ of $\left[\mathrm{Zn}\left(\mathrm{NO}_{3}\right) 2 .{ }_{6} \mathrm{H}_{2} \mathrm{O}\right]$ and $0.047 \mathrm{~g}$ of $\mathrm{AgNO}_{3}$ were dissolved in deionized water $20 \mathrm{ml}$, then dropped of $\mathrm{NaOH}(0.01 \mathrm{M})$ aqueous solution was slowly added with magnetic stirring at $60^{\circ} \mathrm{C}$ for $2 \mathrm{~h}$ at $\mathrm{pH}=8.5$. The precipitate formed was allowed to settle down for $24 \mathrm{~h}$, the solution was put in a stainless steel autoclave for carrying out the hydrothermal treatment at $180^{\circ} \mathrm{C}$ for 4 hours. The stainless steel autoclave was then opened at room temperature and the precipitate was separated and washed repeatedly by deionized water until the $\mathrm{pH}=7$ and sonicated for $10 \mathrm{~min}$. to get uniformly suspended nanostructures suspension. This suspension was centrifuged at $3000 \mathrm{rpm}$ for $10 \mathrm{~min}$. and dried at $80^{\circ} \mathrm{C}$ for $3 \mathrm{~h}$ and then ground to get a fine $\mathrm{Ag}-\mathrm{ZnO}$ powder. The calcination at $350^{\circ} \mathrm{C}$ for $4 \mathrm{~h}$ in programmable furnace to get the $\mathrm{Ag}-\mathrm{ZnO}$ nanostructure ${ }^{24}$.

\section{Photocatalytic study}

The photocatalytic activity of $\mathrm{ZnO}$ and $\mathrm{Ag}-\mathrm{ZnO}$ nanostructure were achieved by degradation of CB dye solution. All the tests were approved under visible light from $400 \mathrm{~mW} . \mathrm{cm}^{-2}$ Xenon lamp. 100mg of $\mathrm{ZnO}$ or $\mathrm{Ag}-\mathrm{ZnO}$ nanostructure was added to (50 ppm/100 ml) CB dye solution then taken and stirred in dark for $120 \mathrm{~min}$. to let the physical adsorption of dye molecules on the surface of catalyst. Also, This experimental setup was then putted in presence of visible light with stirring for 120 minute. The effect of different parameters on $\mathrm{ZnO}$ and $\mathrm{Ag}-\mathrm{ZnO}$ nanostructure were studied such as amount of catalyst, $\mathrm{CB}$ dye concentration and $\mathrm{pH}$ solutions on degradation efficiency, the $\mathrm{pH}$ of the $\mathrm{CB}$ dye solution was methodically adjusted by adding 0.1 $\mathrm{M} \mathrm{NaOH}$ or $\mathrm{HCl}$. The $\mathrm{pH}$ meter used for measured $\mathrm{pH}$ value of the solutions at room temperature. $5 \mathrm{ml}$ of the samples were taken and centrifuged for $5 \mathrm{~min}$. at the rate of $3500 \mathrm{rpm}$ to remove catalyst nanostructure. The CB dye concentration was determined by UV-Visible spectrophotometer from the absorption spectra of all the CB dye degradation samples at $\lambda \max =404 \mathrm{~nm}$, (Fig. 2.) Calibration curve of $\mathrm{CB}$ dye. The percentage of CB dye degradation was calculated by equation:

$\%$ Degradation $=\left(A_{0}-A t\right) / A_{0} \times 100$

Where, $A_{o}$ is the initial $C B$ dye absorbance; At is the absorbance of CB dye at time ( $t$ ). Samples of $\mathrm{CB}$ dye were tested with thermo low-range (0-150) ppm COD test reagent in an TR 300 COD Thermoreactor.

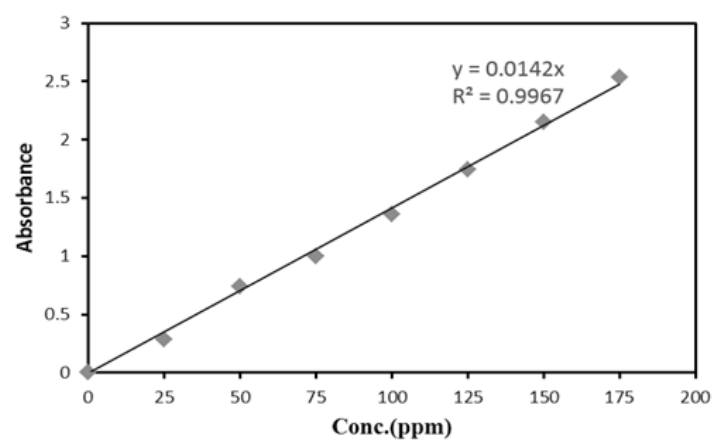

Fig. 2. Calibration curve of $\mathrm{CB}$ dye

Characterization of $\mathrm{ZnO}$ and $\mathrm{Ag}-\mathrm{ZnO}$ nanostructure

The crystalline phase of all nanostructures were characterized by XRD using (XRD-6000, Shimadzu-Japan) with Cu-Ka radiation (0.154056 nm), the XRD pattern was performed from (20-80) ${ }^{\circ}$. Scanning electron microscope (SEM) analysis was performed on nanostructures by Tescan, Vega 3 (Czech) electron microscope with accelerating voltage of $25 \mathrm{kV}$. The roughness of surface was recorded using angstrom AFM (SPM-AA3000, USA). The functional groups of nanostructures were determine by using FTIR(Shimadzu FTIR 8400 s, Japan) analysis in the range $400-4000 \mathrm{~cm}^{-1}$ using $\mathrm{KBr}$ disc. UV-Vis spectrophotometer (UV-1650, Shimadzu, Japan) was used to recording the spectra of prepared nanoparticles in range $200-800 \mathrm{~nm}$. The optical band gap Eg was projected from the UV-Vis-NIR diffuse reflectance spectroscopic (UV-Vis-NIR DRS) determined in a wavelength range from (300-1100) $\mathrm{nm}$ with JASCO V-570 spectrophotometer.

\section{RESULTS AND DISCUSSION}

\section{XRD analysis}

The crystal structure of the $\mathrm{ZnO}$ and 
Ag-ZnO nanostructures were investigated by analyzing the XRD data. X-ray diffraction patterns were shown in Fig. 3. The diffraction peaks were obtained for $\mathrm{Ag}-\mathrm{ZnO}$ was similar to pure $\mathrm{ZnO}$ with low intensity peaks due to silver. In pure $\mathrm{ZnO}$ pattern there are no other summit indicate the presence of the impurity, this is evidence that these particles dual Zinc oxide nanoparticles possess phase one. The average grain size of as prepared $\mathrm{ZnO}$ nanoparticles are found to be $50 \mathrm{~nm}$. Nine peaks appeared at $2 \theta=31.76^{\circ}, 36.25^{\circ}, 34.42^{\circ}, 47.53^{\circ}, 62.86^{\circ}, 56.50^{\circ}$, $66.37^{\circ}, 67.96^{\circ}$, and $69.09^{\circ}$, which correspond to (100), (101), (002), (102),(103), (110), (200), (112) and (201), reflection planes, respectively. All the diffraction peaks can also be well indicate to the hexagonal wurtzite structure of $\mathrm{ZnO}$ (JCPDS no: 36-1451) and pure phase with highly crystalline produced due to very sharp and intense peaks ${ }^{25}$. In the diffraction patterns of $\mathrm{Ag} / \mathrm{ZnO}$ nanostructures, we noticed the major plane (111), (200) and (220) refers to metallic $\mathrm{Ag}$ contend its presence on the ZnO surface, when 3\% Ag nanoparticles was added. The average crystallite sizes were calculated using Scherrer's equation:

$D=0.9 \lambda / \beta \cos \theta$

Where, $\mathrm{D}=$ average crystallite size, $\lambda=$ wavelength of X-ray beam (1.54056 $\AA$ ), $\theta=$ scattering angle in degree, and $\beta=\mathrm{FWHM}$ in radians ${ }^{26}$.

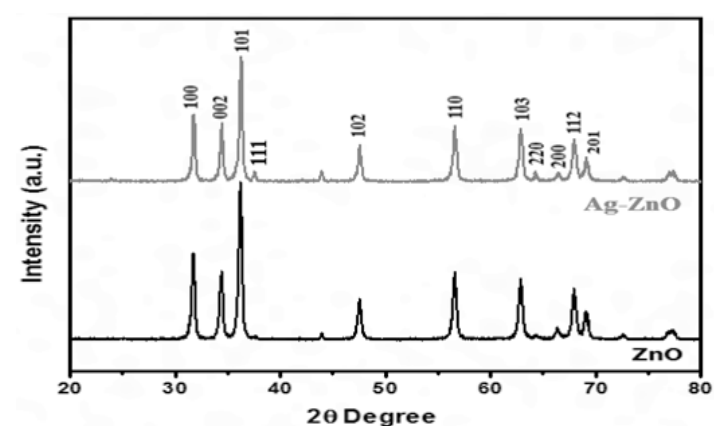

Fig.3. XRD patterns of $\mathrm{ZnO}$ nanoparticles and $\mathrm{Ag}-\mathrm{ZnO}$ nanostructures prepared

\section{FT-IR analysis}

The FT-IR measurements have been carried out using $\mathrm{KBr}$ pellets method in the range 4000-400 $\mathrm{cm}^{-1}$ to approveand identify the formation of $\mathrm{ZnO}$ and $\mathrm{Ag}-\mathrm{ZnO}$ nanostructures as shown in Fig. 4. The absorption band present at $3420 \mathrm{~cm}^{-1}$ correspond to the surface-adsorbed the hydroxyl groups $(\mathrm{O}-\mathrm{H})$ and water. The absorption band present at
$1442 \mathrm{~cm}^{-1}$ and $940 \mathrm{~cm}^{-1}$ correspond to $\mathrm{C}=\mathrm{O}$ and $\mathrm{C}=\mathrm{C}$ bonds respectively ${ }^{27}$. The absorbance peak noticed in the spectra around $470.03 \mathrm{~cm}^{-1}$ and $465.06 \mathrm{~cm}^{-1}$ clearly shows the presence of $\mathrm{Zn}-\mathrm{O}$ and $\mathrm{Ag}-\mathrm{O}$ stretching bond. A last note on FT-IR spectra is the presence of $\mathrm{C}=\mathrm{O}=\mathrm{C}$ peak around $2352 \mathrm{~cm}^{-1}$ which is a common impurity in IR spectra ${ }^{28}$.

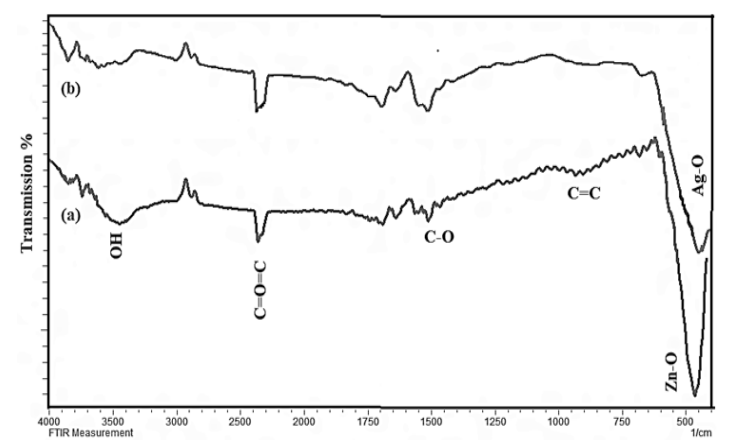

Fig. 4. FTIR spectrum of (a) ZnO Nanoparticles and (b)Ag-ZnO Nanotructure

\section{Atomic Force Microscopy analysis}

The surface morphology of $\mathrm{ZnO}$ nanoparticles prepared also observed by AFM. Fig. 5. shows three dimensional (3D) AFM images and particles size distribution of the $\mathrm{ZnO}$ and $\mathrm{Ag}-\mathrm{ZnO}$ nanostructure scanned over a surface area of $1 \times 1 \mu \mathrm{m}^{2}$ using tapping mode. The AFM image of $\mathrm{ZnO}$ in Fig. 5(a1) shows high uniform distribution of nanoparticles, the statistical roughness analysis (CSPM) shows that the obtained roughness average is $0.363 \mathrm{~nm}$, root mean square roughness is $0.448 \mathrm{~nm}$, surface skewness is -0.308 , and the surface kurtosis is equal to 2.59 . Also the results show that the surface of $\mathrm{ZnO}$ nanoparticles is bumpy and the valleys are more than the peaks of surface. In Fig. 5(b1) the AFM image of Ag-ZnO shows that the got roughness average is $1.08 \mathrm{~nm}$, the root mean square roughness is $1.26 \mathrm{~nm}$, the surface skewness is -0.222 and the surface kurtosis is equal to 4.93 , the results indicating the surface contain different phase of materials and the Ag was incorporated in $\mathrm{ZnO}$ crystal lattice ${ }^{29}$.

\section{SEM analysis}

The morphologies of $\mathrm{ZnO}$ and $\mathrm{Ag}-\mathrm{ZnO}$ nanostructure prepared from SEM and the SEM images of the obtained $\mathrm{Ag}-\mathrm{ZnO}$ nanostructure in $500 \mathrm{~nm}$ was shown in Fig. 6 . The Ag nanoparticles exhibit cubic to be attached with $\mathrm{ZnO}$ wurtize like structure which morphology in the scale of 
$23.89 \mathrm{~nm}^{30}$. The SEM images present the particles of $\mathrm{ZnO}$ nanoparticles with a very wide particle size distribution, Also EDS spectrum of ZnO nanoparticles

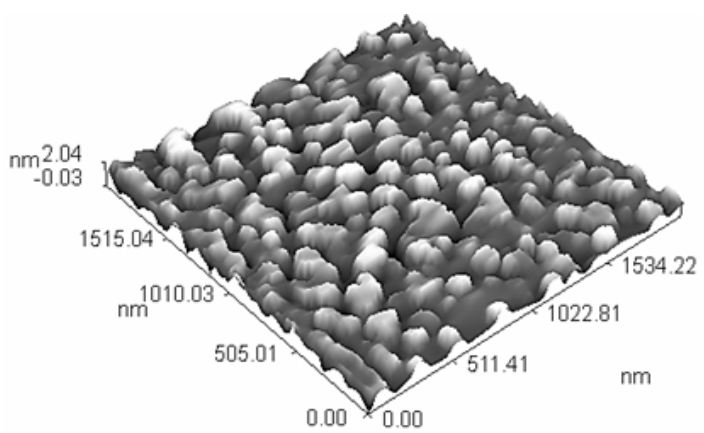

(a1)

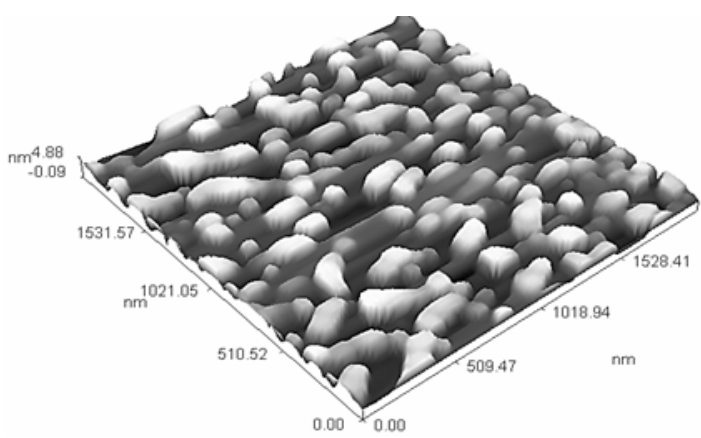

(b1) shown in the (Fig. 6(B)) indicated the composition of different elements which presence of $\mathrm{Zn}, \mathrm{Ag}$ and $\mathrm{ZnO}$ their high purity.

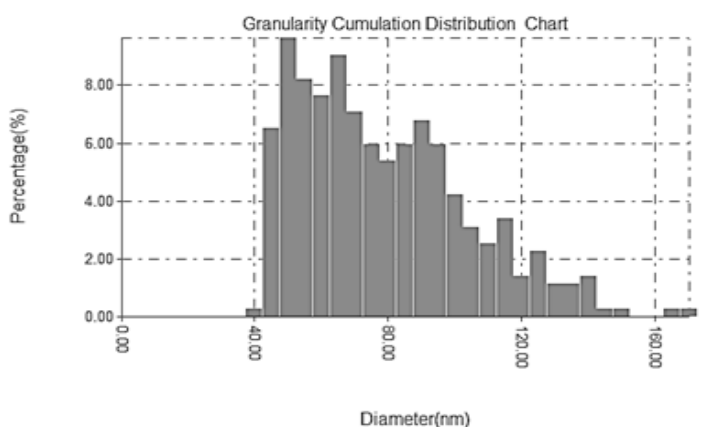

(a2)

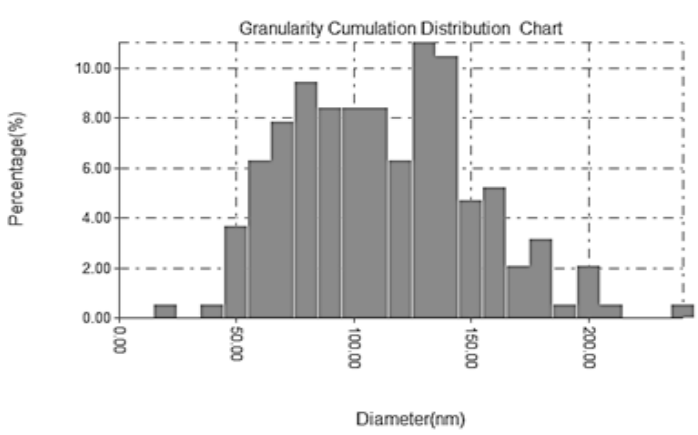

(b2)

Fig. 5. AFM (1). 3D image, (2). Particles size distribution of (a). ZnO nanoparticles, (b). Ag-ZnO nanostructure
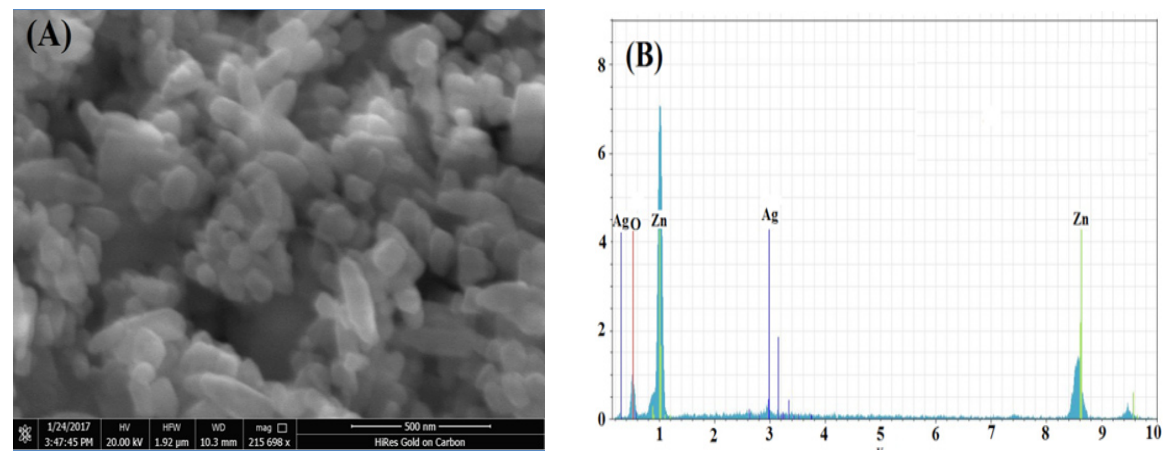

Fig.6. (A). SEM image and (B). EDS of Ag-ZnO nanostructure powder

\section{TEM analysis}

The crystalline, distribution and the particles size of $\mathrm{Ag}-\mathrm{ZnO}$ nanostructure were shown in Fig. 7. The TEM image shows the hexagonal wurtize of $\mathrm{ZnO}$ and cubic structure for Ag nanoparticales with different particle size. The particle size is approximately equal to $20 \pm 60 \mathrm{~nm}$. The fewer aggregation was shown in TEM image that owing to occur the sintering of silver and zinc oxide crystals which is formed through the calcination stage.

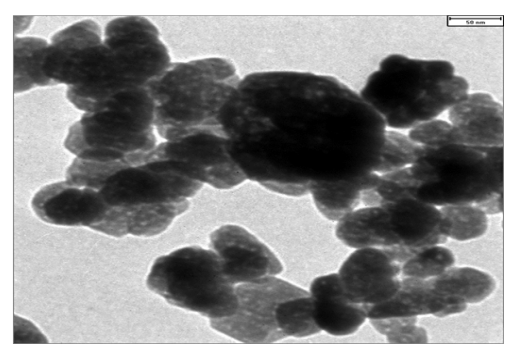

Fig.7:TEM image of Ag-ZnO nanostructure powder 


\section{UV-Vis DRS analysis}

Figure 8. shows the spectrum UV-Visible particles of $\mathrm{ZnO}$ nanoparticles within the range of wavelengths $(300-1100 \mathrm{~nm})$. The quantity of the energy band gap of $\mathrm{ZnO}$ and $\mathrm{Ag}-\mathrm{ZnO}$ nanostructures prepared has been determine by studied of the optical properties of these particles using spectroscopy UV-Visible. The band gap energy of all nanostructures were calculated depended on the absorption spectrum of the sample according to the following equation:

$$
E b g=1240 / \lambda g
$$

Where, Ebg is the band gap energy of the photocatalyst, $\lambda \mathrm{g}$ is the wavelength in $\mathrm{nm}$ used as the absorption edge. the band gap energy decreases from $3.35 \mathrm{eV}$ at $370 \mathrm{~nm}$ for pure $\mathrm{ZnO}$ to $3.29 \mathrm{eV}$ at $376 \mathrm{~nm}$ for $\mathrm{Ag}-\mathrm{ZnO}$, when $\mathrm{Ag}$ doped with $\mathrm{ZnO}$ nanoparticales. The decrease in band gap indicate that the role of $\mathrm{Ag}$ dispersed into $\mathrm{ZnO}$ nanoparticles and recreation on the surface of $\mathrm{ZnO}$ nanocomposite increase the surface area more and this shows that the $\mathrm{Ag}-\mathrm{ZnO}$ has a suitable band gap can used for photocatalytic degradation of dyes ${ }^{31-32}$. Also the band gap energy was determined using Tauc's formula which shows the relationship among absorption coefficient as follows:

$$
(\alpha h v)^{1 / n}=C\left(h v-E_{g}\right)
$$

Where $\alpha$ is the absorption coefficient, $v$ is frequency $(v=c / \lambda, h$ is Planck's constant, $\lambda$ is the wavelength, $c$ light speed, ). $n=1 / 2$, and 2 for indirect and direct optical band gab, respectively. $\mathrm{C}$ is proportionality constant, and $\mathrm{Eg}$ is band gab ${ }^{32}$.

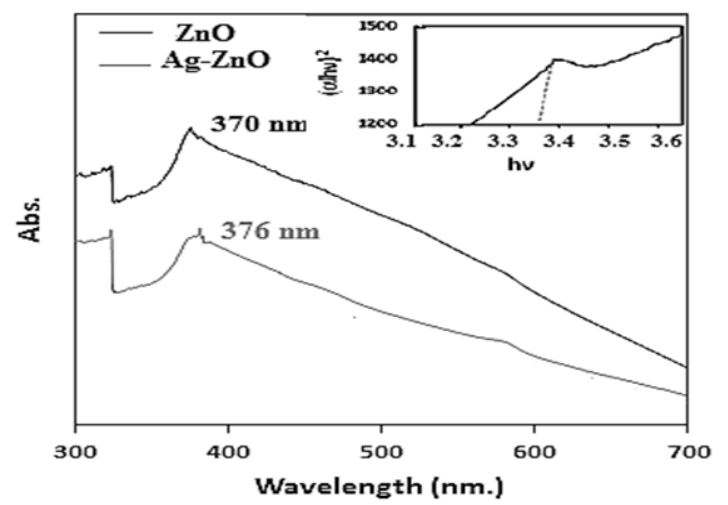

Fig.8: UV-Vis DRS analysis spectrumof $\mathrm{ZnO}$ and $\mathrm{Ag}-\mathrm{ZnO}$ nanostructures and Tauc's plot of the pure $\mathrm{ZnO}$

\section{Photocatalytic activity}

In order to investigate the effectiveness of prepared $\mathrm{ZnO}$ and $\mathrm{Ag}-\mathrm{ZnO}$ nanostructures on degradation of $\mathrm{CB}$ dye under visible light. $\mathrm{ZnO}$, having a high band gap energy which enhanced by added Ag nanoparticles. Xenon lamp which emit a continuous spectrum of light inbetween $300-800 \mathrm{~nm}$ was used as a visible light source. In general, the photodegradation of $\mathrm{CB}$ dye catalyzed by the semiconductors follows pseudo-first-order rate law ${ }^{33}$. Fig. 9. shows the UV-Vis spectrum of $C B$ dye in presence of catalyst with different time often follows pseudo-first-order kinetics shown in Fig.10. can be represented as follows:

$-\mathrm{dC} / \mathrm{dt}=\mathrm{kt}$

The integrated can be as : $\ln \left(C_{0} / C_{t}\right)=k t$

Where is $\mathrm{C}_{0}$ the initial concentration, $\mathrm{C}_{t}$ concentration $\mathrm{CB}$ dye solution at different time and

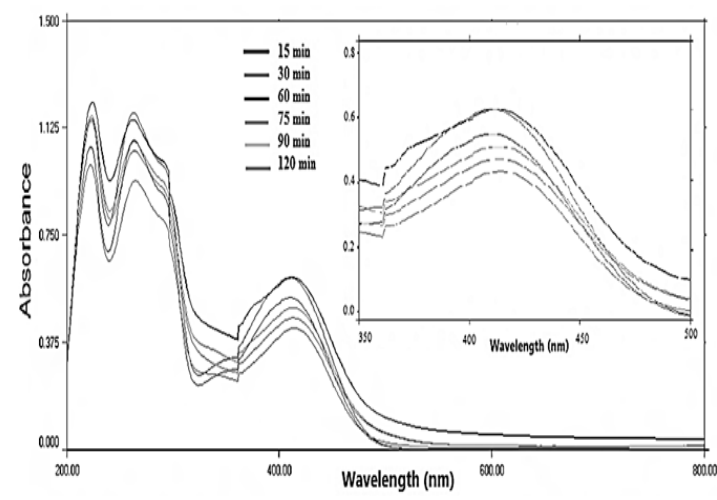

Fig. 9. UV-Vis absorption spectrum of dye at 298k using Ag-ZnO Nanoparticle within different time (catalyst dose:100 $\mathrm{mg} / 100 \mathrm{ml}, \mathrm{CB}$ dye:50 ppm, $\mathrm{pH}=5.1$ )

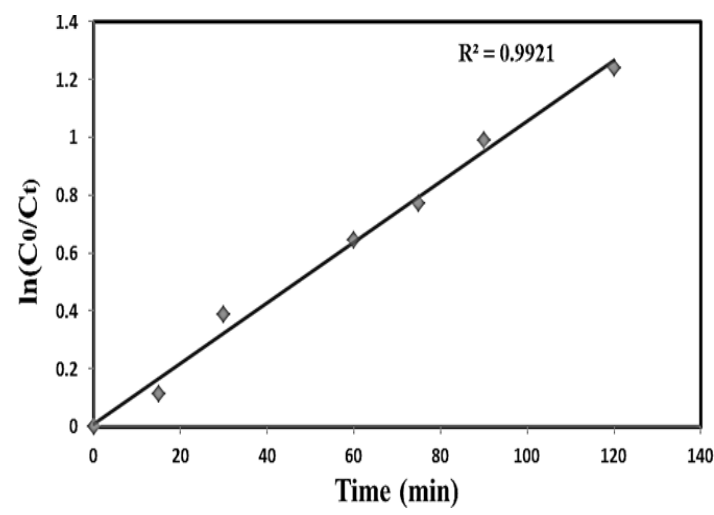

Fig.10. Plot of In (Co/Ct) versus time for photocatalytic degradation of $\mathrm{CB}$ dye using (Ag-ZnO $=100 \mathrm{mg}$, dye cncentration: $50 \mathrm{ppm}, \mathrm{pH}=5.1$ ) under visible irradiation 
$\mathrm{k}$ is the rate constant. The kinetic parameters obtained using the pseudo first order kinetic model corresponding to Fig. 11. The rate constants for $C B$ dye using $\mathrm{Ag}-\mathrm{ZnO}$ as photocatalyst ; $11.46 \times 10^{-3} \mathrm{~min}^{-1}$.

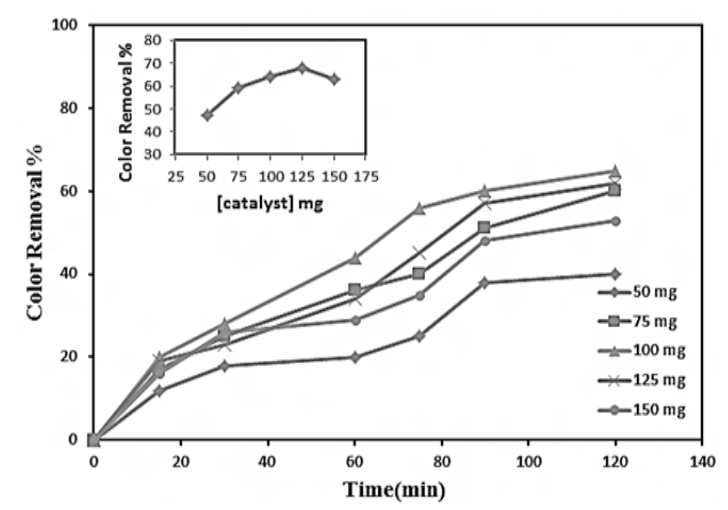

Fig. 11. Effect of Ag-ZnO amount on color removal efficiency at $298 \mathrm{k}$ (dye cncentration: $50 \mathrm{ppm}, \mathrm{pH}=\mathbf{5 . 1}$ )

The color removal efficiency of CB dye using $\mathrm{ZnO}$ as photocatalyst was $43 \%$ at $120 \mathrm{~min}$. the photocatalytic degradation using $\mathrm{Ag}-\mathrm{ZnO}$ nanoparticle as photocatalyst in presence of visible light irradiation was as high as $65 \%$ at $120 \mathrm{~min}$. because of the efficiency of charge carrier separation (electrons and holes) in the excited states that avoids recombination of charge pairs for a extensive time in presence of visible radiation.

\section{Effect of Ag-ZnO loading}

The experiments were performed by taking different amounts in a range $50-150 \mathrm{mg}$ of $\mathrm{Ag}-\mathrm{ZnO}$ with 50 ppm of CB dye concentration constant as shown in Fig.10. The results found the color removals of the CB dye solution were $65 \%$ as $100 \mathrm{mg}$ of $\mathrm{Ag}-\mathrm{ZnO}$ for $100 \mathrm{ml}$ of the CB dye solution, which it shows a radical reduction. As the $\mathrm{Ag}-\mathrm{ZnO}$ amount increase $150 \mathrm{mg}$ the color removal became 53\% .At $25 \mathrm{mg}$ of $\mathrm{Ag}-\mathrm{ZnO}$ amount the color removal became $40 \%$, Therefore when the active sites on the e $\mathrm{Ag}-\mathrm{ZnO}$ catalyst surface increases for the reaction, that lead to increases the rate formation of radical. In the photocatalytic oxidation process, the photo excited $\mathrm{Ag}-\mathrm{ZnO}$ and an electron-hole pair is shaped by follows:

$$
\begin{aligned}
& \mathrm{ZnO} / \mathrm{Ag}+\mathrm{hu}(\text { visble }) \rightarrow \mathrm{ZnO} / \mathrm{Ag}^{*}(\mathrm{e}-) \\
& \mathrm{ZnO} / \mathrm{Ag}^{*}(\mathrm{e}-) \rightarrow \mathrm{ZnO}(\mathrm{e}-\mathrm{CB})+\mathrm{Ag} \\
& \mathrm{e}-\mathrm{CB}+\mathrm{O}_{2} \rightarrow \mathrm{O}_{2}- \\
& \mathrm{h}+{ }_{\mathrm{vb}}+\mathrm{OH} \rightarrow \cdot \mathrm{OH} \\
& \mathrm{O}_{2}-+\cdot \cdot \mathrm{OH}+\text { Dye } \rightarrow \text { Degradation product }
\end{aligned}
$$

Where, e-CB is the electron at the conduction band and $\mathrm{h}+{ }_{\mathrm{VB}}$ is the hole at the valence band. $\mathrm{Ag}-\mathrm{ZnO}\left(\mathrm{e}-\mathrm{CB}\right.$ and $\left.\mathrm{h}+_{\mathrm{VB}}\right)$ is photo excited with the formation of electron and hole then dye was damaged through direct oxidation by formed the hydroxyl radicals and $\mathrm{O} \bullet_{2}$ - radicals as shown in eq. $(9,10)^{19}$. The hydroxyl radicals are produced by these radicals reacted with dye eq.(11). These radicals can react with a superior oxidization with dye (mostly $-\mathrm{N}=\mathrm{N}-$ bond) to produce final products. The decrease in the rate constant after the Ag-ZnO catalyst amount increased as $150 \mathrm{ppm} / 50 \mathrm{ml}$ because the light was scattering and occur reduction in light diffusion through the solution. Through a very high catalyst dose the deactivation of all initiated molecules by crash with molecules in ground state controls the reaction, therefore reducing the rate of reaction ${ }^{32-34}$.

\section{Effect of Initial Dye Concentration}

The effect of initial CB dye concentration was studied under visible light by variable the concentration from 25-125 ppm in presence of (100 $\mathrm{mg} / 100 \mathrm{ml}) \mathrm{Ag}-\mathrm{ZnO}$ as constant on the degradation efficiency of catalyst. The maximum degradation efficiency of CB was recorded at 50 ppm of dye, but decrease for more highly concentrated of dye at 125 ppm as shown in Fig.12. The solutions have been concentrated of dye as 125 ppm or less concentration were nearly completely degraded at this $\mathrm{Ag}-\mathrm{ZnO}$ amount, at this $\mathrm{Ag}-\mathrm{ZnO}$ amount, the dyes with higher concentrations such as 100 or 125 ppm were not fully degraded For example, the $50 \mathrm{ppm}$ the solution was degraded at $65 \%$ after $120 \mathrm{~min}$, while the $125 \mathrm{mg}$ solution was degraded only $45 \%$ after the similar reaction time, on the catalyst the active surface available for reaction is very important for the degradation to have effect, but active sites decrease as the dye concentration was increased for the reaction because of the solution of dye developed more intense colored, so the path length of photons entering the solution decreased therefore only less photons can reach to the catalyst surface and the production of hydroxyl radicals is not enough when the surface of $\mathrm{Ag}-\mathrm{ZnO}$ is more completely covered with dye molecules ${ }^{35}$. 


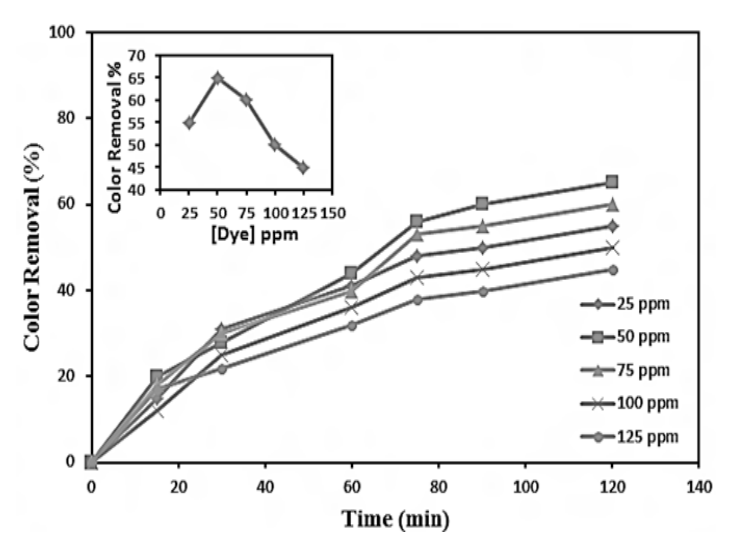

Fig. 12: Effect of initial dye concentration on color removal efficiency at $298 \mathrm{k}(\mathrm{Ag}-\mathrm{ZnO}$ amount: $100 \mathrm{mg}, \mathrm{pH}=5.1)$

\section{Effect of $\mathrm{pH}$}

The $\mathrm{pH}$ factor was most important affecting in this study was carried out by varying $\mathrm{pH}=2,4,6,8$ and 10 using $\mathrm{HCL}$ or $\mathrm{NaOH}$ for adjusted the $\mathrm{pH}$ of solutions. The result is shown in Fig.13. shown the effect of $\mathrm{pH}$ values $(\mathrm{pH} 2-10)$ on the color removal efficiency with time, The minimum removal efficiency was recorded in very alkaline at $\mathrm{pH}=10$ and in very acidic at $\mathrm{pH}=2$.The maximum value obtained in $\mathrm{pH}=5.5$, the effect of $\mathrm{pH}$ occur not only on the surface properties of $\mathrm{Ag}-\mathrm{ZnO}$ nanostructure but similarly occur when separation of dye molecules and hydroxyl radicals formation. In alkaline condition, the Ag-ZnO surface becomes negatively charged, producing an electrostatic repulsion between the negatively charged of dye and the catalyst. In the acidic condition, Ag- $\mathrm{ZnO}$ is exhibits an amphoteric oxide, which can be dissolved in very high acidic aqueous solution to form $\mathrm{Zn}+{ }^{36-37}$.

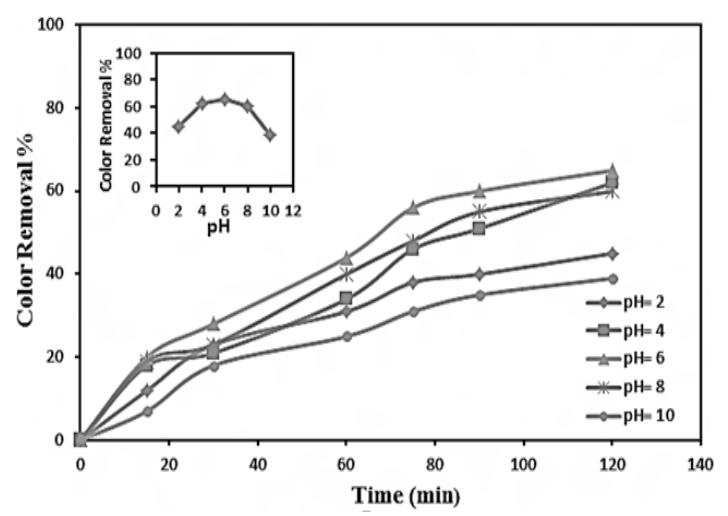

Fig. 13. Effect of different $\mathrm{pH}$ value on the color removal efficiency at 298k (dye concentration: $50 \mathrm{ppm}, \mathrm{Ag}-\mathrm{ZnO}$ amount: $100 \mathrm{mg}, \mathrm{pH}=\mathbf{5 . 1}$ )

\section{Effect of Temperature}

Temperature has been an important role in the photocatalytic process, which directly effects on the degradation of $\mathrm{CB}$ dye process. Fig.14. shows that when the solution temperature increases, the color removal efficiency of CB dye increase when the other experiment conditions stable (50 ppm dye concentration and $100 \mathrm{mg} \mathrm{Ag-ZnO}$ in $100 \mathrm{ml}$ of dye solution, $\mathrm{pH}=5.1$ ), Where the dissociation of the dye was studied at three different temperature levels of $293 \mathrm{k}, 298 \mathrm{k}, 303 \mathrm{k}$ and $308 \mathrm{k}$ was found at $308 \mathrm{k}$ temperature. The CB dye has the largest degradation ${ }^{32}$. Arrhenius equation was used to clarify the relationship between rate consistency and its temperature:

In $\mathrm{k}=\ln \mathrm{A}-\mathrm{Ea} / \mathrm{RT}$

Where, $\mathrm{k}$ : is rate constant, $\mathrm{A}$ : frequency factor, R: gas constant, T: temperature. Fig. 15. shows this effect.

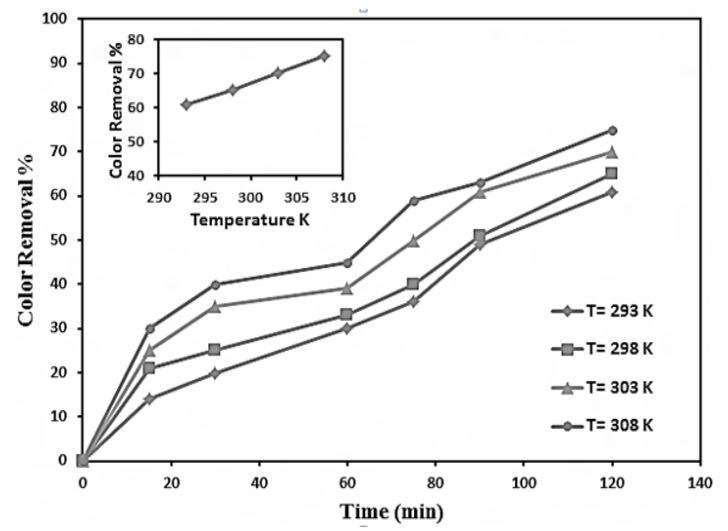

Fig. 14: Effect of Temperature on the color removal efficiency at (dye concentration: 50 ppm , Ag-ZnO amount: 100 mg, pH = 5.1)

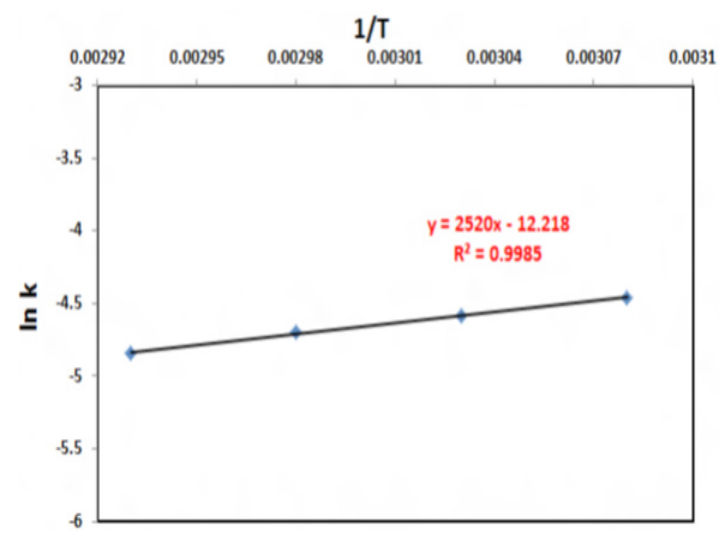

Fig. 15. Arrhenius eqn. (dye concentration: 50 ppm , Ag-ZnO amount : $100 \mathrm{mg}$ and $\mathrm{pH}=\mathbf{5 . 1}$ ) 


\section{COD analysis}

The mineralization of $\mathrm{CB}$ dye is improved by measuring the COD values at different times of irradiation under enhanced conditions. The percentage of COD removal is $40 \%$ after
120 minutes. The results indicates that the almost complete mineralization of $\mathrm{CB}$ dye molecules compare with color removal under visible light is observed was $65 \%$ after 120 min as shown in Figure 16.

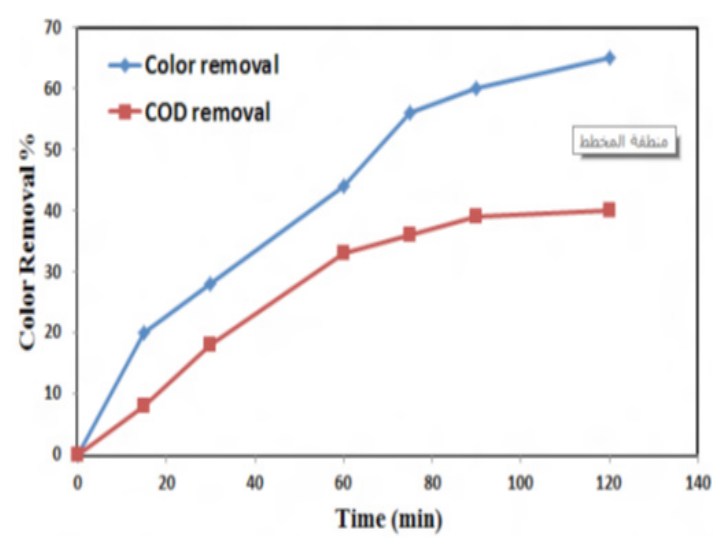

Fig.16. Color removal and COD removal of degradation of $C B$ dye concentration: 50 ppm , Ag-ZnO dose: $100 \mathrm{mg}$ at $\mathrm{pH}=5.1$ and $\mathrm{T}=298 \mathrm{~K}$

\section{CONCLUSION}

$\mathrm{ZnO}$ and $\mathrm{Ag}$ doped $\mathrm{ZnO}$ nanostructures were successfully prepared by hydrothermal method. The structural properties and particle size of $\mathrm{ZnO}$ and $\mathrm{Ag}-\mathrm{ZnO}$ nanostructure was studied using XRD, SEM,TEM, FT-IR and UV-Vis spectroscopy. The pure hexagonal wurtzite structure of $\mathrm{ZnO}$ and cubic shape for Ag were confirmed from XRD studies. In addition, the TEM results showed that the average particle size $20 \pm 60 \mathrm{~nm}$ of $\mathrm{Ag}-\mathrm{ZnO}$ nanostructure. The formation of hexagonal wurtize nanoparticles shape for $\mathrm{ZnO}$ and cubic shape for Ag were observed from SEM studies. The FT-IR showed a broad absorption band related to $\mathrm{Ag}-\mathrm{O}$ vibration band. The band gap of the $\mathrm{ZnO}$ nanoparticles was valued from the UV-Vis absorption. The photocatalytic removal efficiency under visible light $65 \%$ which show higher removal efficiency than COD analysis.

\section{REFERENCES}

1. Salahuddin N A, El-Kemary M, Ibrahim E M, Nanosci. and Nanotech., 2015, 5, 82-88.

2. Pareek S S, Pareek K, IOSR. JAP., 2013, 3, $16-24$.

3. Ahmad M, Ahmed E, Hong Z, Ahmed W, Elhissi A, Khalid N, Ultrasonicssono chemistry., 2014, 21, 761-773.

4. Nirmala M, Nair M G, Rekha K, Anukaliani A, Samdarshi S, Nair R G, Afr. J. Basic Appl. Sci., 2010, 2, 161-166.

5. Elamin N , Elsanousi A, J. Appl. and Ind. Sci., 2013, 1, 32-35.

6. Rout C S, Krishna S H, Vivekchand S, Govindaraj A, Rao C, Chem. Phys. Lett., 2006, 418,586-590.

7. Hwang D K, Oh M S, Lim J H, Choi Y S, Park S J, Appl. Phys. Lett., 2007, 91, 121113.

8. Jiang C, Sun X, Lo G, Kwong D, Wang J Appl. Phys. Lett., 2007, 90, 263501.
9. Al-Taweel S S, Saud H R., J. Chem. and Pharm. Res., 2016, 8, 620-626.

10. Soltaninezhad M, Aminifar A, International J. Nano Dimension., 2011, 2, 137-145.

11. Ramasubbu A, Karunakaran K, Vasanthkumar S, Int. J. Nano Dimension., 2012, 2, 171-176.

12. Shah A, Manikandan E, Ahmed M B, Irdosh M, Chauhan A, Murli C, Gadkari S, In Nano Ag-doped ZnO particles magnetic, optical and structural studies, AIP Conference Proceedings, 2013, 430-431.

13. Labiadh H, Chaabane T B, Balan L, Becheik N, Corbel S, Medjahdi G, Schneider R, Appl. Catalysis B: Environ., 2014, 144, 29-35.

14. Alkaim A F, Dillert R, Bahnemann D W, Environ. Tech., 2015, 36, 2190-2197.

15. Ibupoto $\mathrm{ZH}$, Khun K, Eriksson M, AISalhi M, Atif M, Ansari A, Willander M, Mater., 2013, 6, 3584-3597. 
16. Alkaim A F, KandielT A, Dillert R, Bahnemann D W, Environ. Tech. (United Kingdom)., 2016, 37, 2687-2693.

17. Kang D S, Lee H S, Han S K, Srivastava V, Babu E S, Hong S K, Kim M J, Song $\mathrm{J} \mathrm{H}$, Song J H, Kim H, Kim D, J. Alloys and Compounds., 2011, 509, 5137-5141.

18. GhorbaniH R, Mehr F P, Pazoki H, Rahmani B M, Orient. J. Chem., 2015, 31,1219-1221.

19. Yue S, Yan Z, SHi Y, Ran G, Mater. Lett., 2013, 98, 246-249.

20. Nejati K, Rezvani Z, Pakizevand R, Inter. Nano Lett., 2011, 1, 75.

21. Byrappa K, Adschiri T, Progress in Crystal Growth and Characterization of Materials, 2007, 53, 117-166.

22. Hiromichi H, Yukiya H, Review, Mater., 2010, 3, 3794-3817.

23. Baruah S, Dutta J, Sci. and Technol. Adv. Mater., 2009, 10, 013001.

24. Jia Zg, Peng Kk, LiYh, Zhu Rs, Transactions of Nonferrous Metals Society of China., 2012, 22, 873-878.

25. Bandekar G, Rajurkar N S, Mulla I S, Mulik U P, Amalnerkar D P, Adhyapak P V, Appl. Nanosci., 2013, 4, 199-208.

26. Jasso-Salcedo A B, Palestino G, EscobarBarrios V A, J. Catalysis, 2014, 318, 170-178.
27. Saoud K, Alsoubaihi R, Bensalah N, Bora T, Bertin M, Dutta J, Mater. Res. Bulletin., 2015, 63, 134-140.

28. Ramimoghadam D, Hussein M Z B, TaufiqYap Y H, Chemistry Central J., 2013, 7, 71.

29. Dehimi M, Touam T, Chelouche A, Boudjouan F, Bouasla A, Djouadi D, Fischer A, Boudrioua A, Doghmane A, Inter. J. Natural Sci. Res., 2016, 4, 15-28.

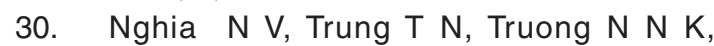
Thuy D M, Open J. Synthesis Theory and Applications., 2012, 01, 18-22.

31. Fageria P, Gangopadhyay S, Pande S, RSC Adv., 2014, 4, 24962.

32. Kuriakose S, Choudhary V, Satpati B, Mohapatra S, Beilstein j.J. nanotech., 2014, 5, 639-50.

33. Al-Hayder L S J, Al-Hussainawy M K, Int. J. Chem. Tech. Res., 2016, 9, 337-344.

34. Nagaraja R, Kottam N, Girija C R, Nagabhushana B M, Powder Tech., 2012, 215-216, 91-97.

35. Vijay A, Nihalani S, Tripathi N, Bhardwaj S, Int. J. Chem. Sci., 2013, 11, (2).150-155.

36. Jia Z, Miao J, Lu H B, Habibi D, Zhang W C, Zhang L C, J. the Taiwan Institute of Chemical Engineers., 2016, 60, 267-274.

37. Al-Hayder L S J, AL-Juboory M H J, J. Chem. and Pharm. Res., 2015, 7, 1138-1144. 